J. Dairy Sci. 97:4824-4831

http://dx.doi.org/10.3168/jds.2014-8240

(C) American Dairy Science Association ${ }^{\circledR}, 2014$.

\title{
The effect of probiotics (Lactobacillus rhamnosus HN001, Lactobacillus paracasei LPC-37, and Lactobacillus acidophilus NCFM) on the availability of minerals from Dutch-type cheese
}

\author{
Marek Aljewicz, ${ }^{* 1}$ Ewa Siemianowska,† Grażyna Cichosz, ${ }^{*}$ and Elżbieta Tońskał \\ *Department of Dairy Science and Quality Management, Faculty of Food Science, \\ †Department of Safety, and \\ ‡Department of Science of Commodities and Evaluation of Food Quality, Faculty of Food Science, University of Warmia and Mazury in Olsztyn, \\ 10-726 Olsztyn, Poland
}

\begin{abstract}
The use of probiotic cultures in the production of Dutch-type cheeses did not lead to significant changes in their chemical composition but it lowered their acidity. The availability of calcium and magnesium analyzed by in vitro enzymatic hydrolysis was 19 and $35 \%$, respectively; the availability of phosphorus was significantly higher, at $>90 \%$. The use of probiotic cultures significantly increased the availability of calcium $(\sim 2.5 \%)$, phosphorus $(\sim 6 \%)$, and magnesium $(\sim 18 \%)$. The in vitro method supports accurate determination of the effect of the Lactobacillus spp. cultures on the availability of mineral compounds ingested with Dutchtype cheese.
\end{abstract}

Key words: Lactobacillus, probiotic, availability, mineral, cheese

\section{INTRODUCTION}

Probiotic cultures are defined as live microorganisms which, when administered in adequate amounts, confer a health benefit on the host (FAO/WHO, 2006). Numerous clinical tests have demonstrated the beneficial effects of probiotic cultures on the gastrointestinal tract (by alleviating symptoms of enteritis and irritable bowel syndrome) and the immune system (Kneifel and Salminem, 2011). Probiotic strains produce metabolites (organic acids, diacetyl, ethanol, hydrogen peroxide, bacteriocins, antibiotics, and carbon dioxide) that stimulate the growth of large intestinal microflora and the immune system. The effectiveness and type of the resulting health benefits are directly determined by the probiotic strain composition, bacterial counts, and the applied carrier.

The effect of probiotic cultures on the bioavailability of mineral compounds is an equally important but

Received April 15, 2014.

Accepted April 19, 2014.

${ }^{1}$ Corresponding author: marek.aljewicz@uwm.edu.pl often overlooked factor. Bacteria proliferating in the intestines use nutrients, including mineral compounds in the digesta, for growth. Changes in the composition and abundance of microflora lead to variations in the bioavailability of mineral compounds (Kwong and Kitts, 2003; Ghanem et al., 2004).

Dairy products are the major $(\sim 70 \%)$ source of calcium in the human diet (Karczmarewicz et al., 2002). Calcium and other mineral compounds are also supplied with foods of plant origin and water, but the calcium content of those sources is significantly lower, at 16 and $\sim 7 \%$, respectively (Guéguen and Pointillart, 2000). Unlike other foods, dairy products do not contain phytates, oxalates, uronic acids, or insoluble dietary fiber fractions, which produce insoluble complexes and decrease the bioavailability of mineral compounds (Wolf et al., 2000).

Ripened cheeses have acceptable sensory characteristics and constitute an abundant source of mineral compounds. Yet the minerals found in ripened cheeses are not always readily available to the human body. The bioavailability of mineral compounds from ripened cheeses is determined by cheese type and the applied production technology, the content of organic acids, the presence of various casein fractions $\left(\alpha_{\mathrm{S}^{-}}, \alpha_{\mathrm{S}^{-}}\right.$, and $\beta-\mathrm{CN})$ and their degradation products, fat content, and FA structure (Guéguen and Pointillart, 2000; Kłobukowski et al., 2009).

Bioavailability is defined as the quantity of mineral compounds and trace elements that can be released (digested), absorbed, and metabolized by the human body. The digestibility of food components is determined with the use of in vivo and in vitro models. The in vitro method relies on enzymatic hydrolysis and an artificial model that simulates the conditions inside the gastrointestinal tract. It is used to determine the degree to which mineral compounds become available (bioavailable) to the human body.

The bioavailability of various mineral compounds and trace elements present in dairy products, including ripened cheeses, is widely discussed in literature. 
But our knowledge about the bioavailability of calcium, magnesium, and phosphorus from ripened cheeses containing probiotic cultures remains limited. For this reason, the objective of the current study was to determine the effect of 3 probiotic cultures, Lactobacillus rhamnosus HN001 (HN001), Lactobacillus paracasei LPC-37 (LPC37) and Lactobacillus acidophilus NCFM (NCFM), on the availability of calcium, magnesium, and phosphorus from Gouda-type cheese.

\section{MATERIALS AND METHODS}

\section{Experimental Design}

The experimental material comprised ripened cheese produced in an industrial plant in Gizycko, Poland. Dutch-type cheese (control and experimental) were produced from 10,000 L (each) of premium class milk, which was thermized at $65^{\circ} \mathrm{C}$ for $15 \mathrm{~s}$ and cooled to $4^{\circ} \mathrm{C}$. Milk was bactofugated, pasteurized at $72.5^{\circ} \mathrm{C}$ for $15 \mathrm{~s}$, and standardized to $3.0 \%$ fat content. It was tempered to $31^{\circ} \mathrm{C}$ and inoculated with the cheese starter culture and probiotic bacteria. Warmed milk was combined with $3 \mathrm{~kg}$ of calcium chloride (Ciech, Warsaw, Poland), $110 \mathrm{~mL}$ of coloring agent, $500 \mathrm{~mL}$ of lysozyme (Afilact, Chr. Hansen, Czastkow Mazowiecki, Poland), deepfrozen Choozit classic 111 cheese starters $(0.06 \%$ vol/ vol; DuPont, Poznan, Poland), and HN001 (0.03\% vol/ vol), NCFM (0.03\% vol/vol), or LPC37 (0.03\% vol/ vol; DuPont) probiotic cultures with $430 \mathrm{~mL}$ of rennet (Chymax, Chr. Hansen) then added directly to batches of experimental cheese. Every phase of the production process was consistent with industry standards and according to Dutch cheese. After brining, the cheeses were wrapped in Cryovac (Duchnice, Poland) heat shrink, oxygen barrier bags and cold stored under controlled conditions. The cheeses were ripened for $6 \mathrm{wk}$ at a temperature of $12^{\circ} \mathrm{C}$ and relative humidity of $85 \%$. They were stored at $4^{\circ} \mathrm{C}$ and relative humidity of $85 \%$. Samples of brined cheeses ripened for 6 wk and stored for 3 mo were collected for analysis. Polish consumers prefer cheeses with a mild taste and a delicate aroma. Because of this, cheeses ripened for 6 wk were analyzed in the study.

\section{Chemical Composition}

Grated cheese samples were analyzed in triplicate to determine their salt content by the Volhard method (AOAC International, 2005; method 975.20), fat content by the Van Gulik method (ISO, 2008), and moisture content by oven-drying at $102^{\circ} \mathrm{C}$ (AOAC International, 2005; method 926.08). The pH of the cheese slurry, prepared by blending $10 \mathrm{~g}$ of grated cheese with $10 \mathrm{~mL}$ of $\mathrm{H}_{2} \mathrm{O}$, was measured with a $\mathrm{pH}$ meter (Elmetron $\mathrm{CP}$ 501, Zabrze, Poland; electrode: Inode, Zabrze, Poland) after calibration with $\mathrm{pH} 4.0$ and 7.0 buffers (Merck, Darmstadt, Germany).

\section{Mineral (Ca, P, Mg) Content of Cheese (Mineralization Stage)}

Cheese samples of $1.5 \mathrm{~g}$ were weighed (accurate to $0.0001 \mathrm{~g}$ ), placed in 500-mL Kjeldahl flasks, combined with concentrated $\mathrm{HNO}_{3}$ (Suprapure, Merck), and $\mathrm{HClO}_{4}$ (Ultrapure, JT Baker, Deventer, the Netherlands; 3:1) and left to stand for $30 \mathrm{~min}$. The samples were mineralized (Buchi K-439, Flawil, Switzerland) until a colorless solution was obtained. The samples were cooled and transferred to a volumetric flask containing $50 \mathrm{~mL}$ of ultrapure deionized water (Merck).

The calcium and magnesium content of cheese samples was determined by atomic absorption spectrometry in an air-acetylene flame using the iCE 3000 Series Atomic Absorption Spectrometer (Thermo-Scientific, Hemel Hempstead, UK), a deuterium lamp for background correction, and cathode lamps suitable for each element. Concentrations of $\mathrm{Ca}^{2+}$ were determined by combining the samples with $10 \%$ aqueous solution of lanthanum chloride to obtain $\mathrm{La}^{3+}$ concentrations of $0.5 \%$ in each sample (Whiteside, 1979). Phosphorous content was determined by the molybdenum method with hydroquinone and sulfate using spectrophotometer Helios $\beta$ (Unicam, Cambridge, UK) at $\lambda=460$ to $480 \mathrm{~nm}$ (PKN, 1999).

\section{Availability of Minerals from Cheeses}

Mineral availability was determined by enzymatic hydrolysis in vitro in a system that simulates the conditions in the human gastrointestinal tract. Cheese samples of approximately $1.5 \mathrm{~g}$ (accurate to $0.0001 \mathrm{~g}$ ) were mixed with $50 \mathrm{~mL}$ of deionized water, $\mathrm{pH}$ was adjusted to 2.0 with $1 \mathrm{M} \mathrm{HCl}$ (Suprapure, Merck), and 1.6 $\mathrm{mL}$ of pepsin solution (16 g of pepsin, P-7000, SigmaAldrich, St. Louis, MO, in $100 \mathrm{~mL}$ of deionized water) was added. The mixture was incubated in a shaking water bath (Julabo Sw 22, Labortechnik GmbH, Seelbach, Germany) at $37^{\circ} \mathrm{C}$ for $2 \mathrm{~h}$ (shaking frequency adjustable to $100 \mathrm{rpm}$ ). The solution was neutralized to $\mathrm{pH} 6.8$ to 7.0 with $6 \% \mathrm{NaHCO}_{3}$ (Merck), and a solution of pancreatin and bile salts $[0.4 \mathrm{~g}$ of pancreatin (Sigma-Aldrich) in $100 \mathrm{~mL}$ of $0.1 \mathrm{M} \mathrm{NaHCO}_{3}$ and $2.5 \mathrm{~g}$ of bile salts (Sigma-Aldrich) in $0.1 \mathrm{M} \mathrm{NaHCO}_{3}(\mathrm{POCH}$, Gliwice, Poland)] was added at a rate of $15.8 \mathrm{~mL}$ per every $50 \mathrm{~mL}$ of the reaction solution. The samples were incubated at $37^{\circ} \mathrm{C}$ for $2 \mathrm{~h}$ (shaking frequency adjustable to $100 \mathrm{rpm}$ ) and centrifuged at 5,000 $\times g$ for $15 \mathrm{~min}$ at 


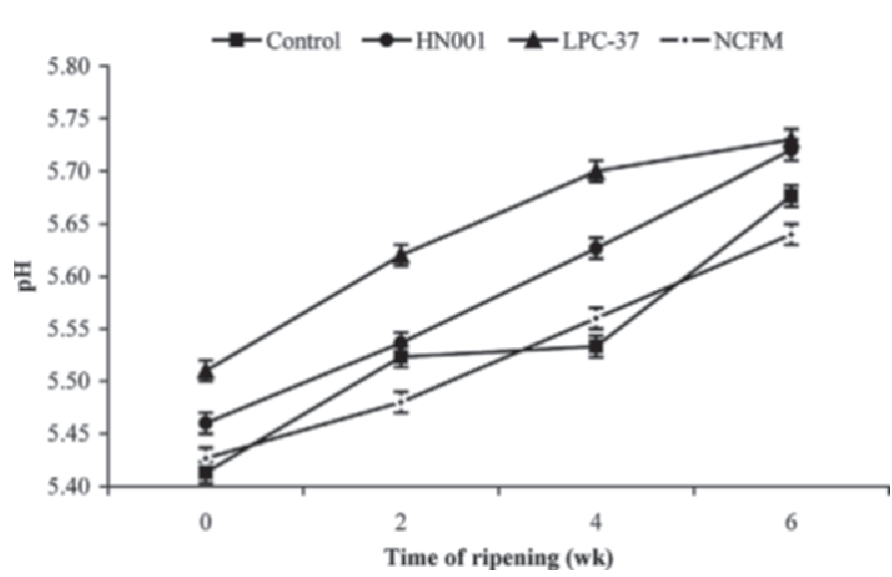

Figure 1. Change in the $\mathrm{pH}$ value in Dutch-type cheese after brining $(0 \mathrm{wk})$ and 2,4 , and 6 wk of ripening. Results are significant $(P<0.05)$ and are expressed as mean $\pm \mathrm{SD} ; \mathrm{n}=3$ sets. Control $=$ control cheese only with starter cultures; HN001 = cheese with starter cultures Choozit classic and Lactobacillus rhamnosus HN001(DuPont, Poznan, Poland); LPC-37 = cheese with starter cultures Choozit classic and Lactobacillus paracasei LPC-37 (DuPont); NCFM = cheese with starter cultures Choozit classic and Lactobacillus acidophilus NCFM (DuPont).

Lactobacillus spp. counts remained relatively similar in NCFM and LPC37 experimental cheeses. Unlike in LPC37 and NCFM cheeses, a significant increase (1 $\left.\log _{10} \mathrm{cfu} / \mathrm{g}\right)$ in Lactobacillus spp. counts was observed in the HN001 cheese. After 3 mo of storage, Lactobacillus spp. counts increased significantly $(P<0.05)$ in control cheeses and in NCFM $\left(0.2 \log _{10} \mathrm{cfu} / \mathrm{g}\right)$, but decreased to 0.74 and $\sim 1.2 \log _{10} \mathrm{cfu} / \mathrm{g}$ in LPC37 and HN001, respectively.

\section{Availability of Calcium from Dutch-Type Cheeses}

The average calcium content of all cheeses was determined at $938 \mathrm{mg} / 100 \mathrm{~g}$ immediately after brining (Table 3). The availability of calcium from the analyzed products was low $(\sim 19 \%)$ in the process of in vitro

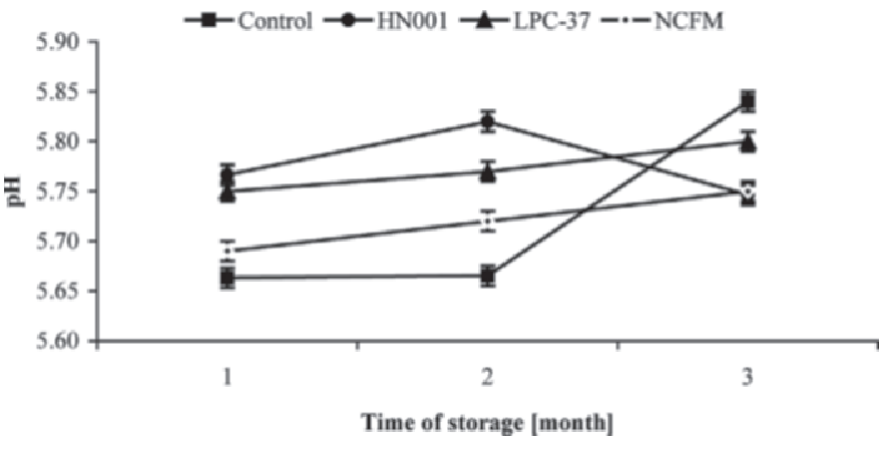

Figure 2. Change in the $\mathrm{pH}$ value in Dutch-type cheese after 1 , 2 , and 3 mo of storage. Results are significant $(P<0.05)$ and are expressed as mean $\pm \mathrm{SD} ; \mathrm{n}=3$ sets. Control $=$ control cheese only with starter cultures; HN001 = cheese with starter cultures Choozit classic and Lactobacillus rhamnosus HN001 (DuPont, Poznan, Poland); LPC$37=$ cheese with starter cultures Choozit classic and Lactobacillus paracasei LPC-37 (DuPont); NCFM = cheese with starter cultures Choozit classic and Lactobacillus acidophilus NCFM (DuPont).

enzymatic hydrolysis (in a model simulating the conditions inside the human gastrointestinal tract). The addition of probiotic cultures significantly $(P<0.05)$ increased $(\sim 2.5 \%)$ the availability of calcium relative to the control. A decrease (not statistically significant) in the availability of calcium from both experimental and control cheeses was observed during ripening and storage.

\section{Availability of Magnesium from Dutch-Type Cheeses}

After brining, the average content of magnesium in all cheeses was determined at $34 \mathrm{mg} / 100 \mathrm{~g}$. In the process of in vitro enzymatic hydrolysis, the availability of magnesium was estimated at $\sim 35 \%$. The addition of probiotic cultures LPC37, NCFM, and HN001 resulted in a significant $(P<0.05)$ increase in the availability of magnesium relative to control at 24,20 , and $10 \%$, respectively. A similar correlation was noted in cheeses

Table 2. Viability of Lactobacillus spp. in Dutch-type cheese after brining (0 d), 6 wk of ripening, and 3 mo of storage ${ }^{1}$

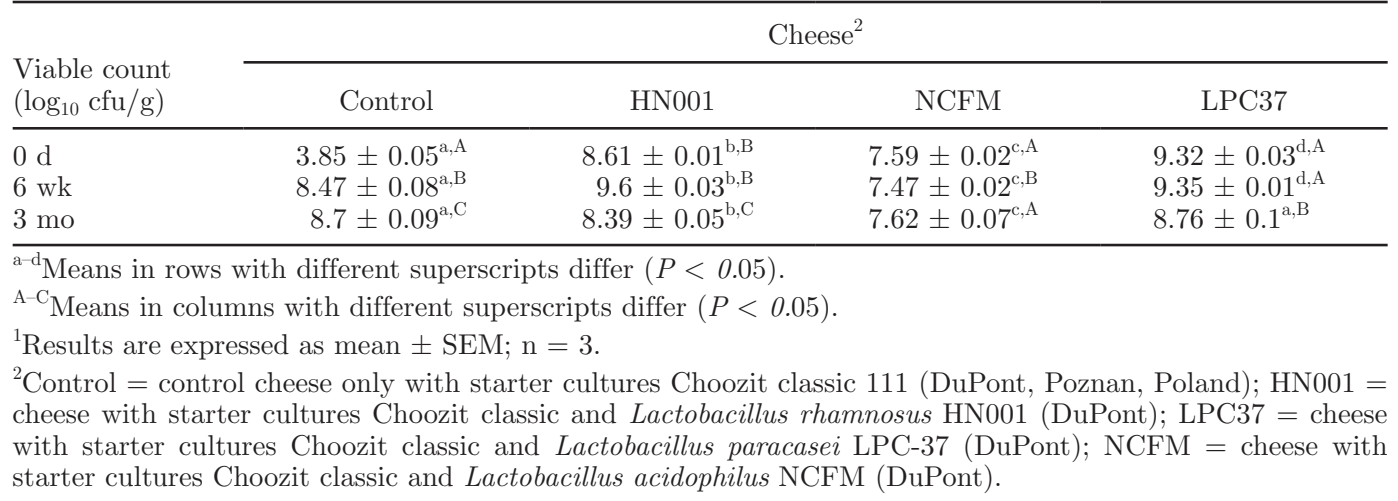


Table 3. Mineral content (mg/100 g) and changes in mineral availability from Dutch-type cheese after brining ( 0 d), 6 wk of ripening, and 3 mo of storage ${ }^{1}$

\begin{tabular}{|c|c|c|c|c|c|c|c|}
\hline \multirow[b]{2}{*}{ Cheese $^{2}$} & \multirow{2}{*}{$\begin{array}{c}\begin{array}{c}\text { Before in vitro } \\
\text { hydrolysis }\end{array} \\
0 \mathrm{~d}\end{array}$} & \multicolumn{3}{|c|}{ After in vitro hydrolysis } & \multicolumn{3}{|c|}{ Amount of mineral released } \\
\hline & & $0 \mathrm{~d}$ & $6 \mathrm{wk}$ & $3 \mathrm{mo}$ & 0 & $6 \mathrm{wk}$ & $3 \mathrm{mo}$ \\
\hline $\mathrm{Ca}$ & $903.041 \pm 12.29^{\mathrm{a}, \mathrm{A}}$ & $127.711 \pm 3.16^{\mathrm{b}, \mathrm{A}}$ & $139.336 \pm 3.45^{\mathrm{b}, \mathrm{A}}$ & $175.578 \pm 5.71^{\mathrm{c}, \mathrm{A}}$ & 14 & 15 & 19 \\
\hline $\mathrm{P}$ & $551.016 \pm 3.89^{\mathrm{a}, \mathrm{A}}$ & $553.503 \pm 0.89^{\mathrm{bc}, \mathrm{A}}$ & $561.037 \pm 0.90^{\mathrm{b}, \mathrm{A}}$ & $535.401 \pm 6.88^{\mathrm{c}, \mathrm{A}}$ & 100 & 102 & 97 \\
\hline $\mathrm{Mg}$ & $32.456 \pm 0.71^{\mathrm{a}, \mathrm{A}}$ & $6.688 \pm 0.66^{\mathrm{b}, \mathrm{A}}$ & $6.715 \pm 0.66^{\mathrm{b}, \mathrm{A}}$ & $6.64 \pm 0.14^{\mathrm{b}, \mathrm{A}}$ & 21 & 21 & 20 \\
\hline $\mathrm{P}$ & $563.382 \pm 6.19^{\mathrm{a}, \mathrm{B}}$ & $476.552 \pm 4.6^{\mathrm{b}, \mathrm{B}}$ & $507.957 \pm 4.14^{\mathrm{c}, \mathrm{B}}$ & $524.434 \pm 2.37^{\mathrm{d}, \mathrm{B}}$ & 85 & 90 & 93 \\
\hline $\mathrm{Mg}$ & $32.884 \pm 0.72^{\mathrm{a}, \mathrm{A}}$ & $22.935 \pm 0.8^{\mathrm{b}, \mathrm{B}}$ & $21.642 \pm 3.69^{\mathrm{b}, \mathrm{B}}$ & $22.145 \pm 0.26^{\mathrm{b}, \mathrm{B}}$ & 70 & 66 & 67 \\
\hline \multicolumn{8}{|l|}{ LPC37 } \\
\hline $\mathrm{Ca}$ & $980.549 \pm 5.69^{\mathrm{a}, \mathrm{B}}$ & $172.418 \pm 5.08^{\mathrm{b}, \mathrm{B}}$ & $124.888 \pm 0.52^{\mathrm{c}, \mathrm{C}}$ & $121.643 \pm 2.37^{\mathrm{c}, \mathrm{C}}$ & 18 & 13 & 12 \\
\hline $\mathrm{P}$ & $569.914 \pm 7.40^{\mathrm{a}, \mathrm{B}}$ & $562.802 \pm 5.60^{\mathrm{a}, \mathrm{C}}$ & $569.361 \pm 5.13^{\mathrm{a}, \mathrm{C}}$ & $629.481 \pm 4.14^{\mathrm{b}, \mathrm{C}}$ & 99 & 100 & 110 \\
\hline $\mathrm{Mg}$ & $27.525 \pm 1.06^{\mathrm{a}, \mathrm{B}}$ & $12.828 \pm 0.56^{\mathrm{b}, \mathrm{C}}$ & $24.518 \pm 0.36^{\mathrm{c}, \mathrm{B}}$ & $39.298 \pm 2.34^{\mathrm{d}, \mathrm{C}}$ & 47 & 89 & 99 \\
\hline \multicolumn{8}{|l|}{ NCFM } \\
\hline
\end{tabular}

${ }^{\mathrm{a}-\mathrm{d}}$ Means in rows with similar superscripts do not differ $(P<0.05)$.

${ }^{\mathrm{A}-\mathrm{D}}$ Means in column with similar superscripts do not differ $(P<0.05)$.

${ }^{1}$ Results are expressed as mean $\pm \mathrm{SEM} ; \mathrm{n}=3$.

${ }^{2}$ Control $=$ control cheese only with starter cultures Choozit classic 111 (DuPont, Poznan, Poland); HN001 = cheese with starter cultures Choozit classic and Lactobacillus rhamnosus HN001 (DuPont); LPC37 = cheese with starter cultures Choozit classic and Lactobacillus paracasei LPC-37 (DuPont); NCFM = cheese with starter cultures Choozit classic and Lactobacillus acidophilus NCFM (DuPont).

after 3 mo of storage. The availability of magnesium was highest after 3 mo of storage and lowest after brining (Table 3).

\section{Availability of Phosphorus from Dutch-Type Cheeses}

The average content of phosphorus in cheeses after brining was determined at $573 \mathrm{mg} / 100 \mathrm{~g}$. In the process of in vitro enzymatic hydrolysis, the availability of phosphorus reached 89 and $\sim 96 \%$ from control and experimental cheeses, respectively. The addition of HN001 led to a minor increase $(2 \%)$ in phosphorus availability. The availability of phosphorus was similar $(\sim 98 \%)$ after 3 mo of storage (Table 3$)$.

\section{DISCUSSION}

The influence of bacterial cultures, including probiotics, on changes in the availability of mineral compounds from food products has been explored by a growing number of research studies (Henry, 1995; Bronner and Pansu, 1999; Guéguen and Pointillart, 2000; Tsuchita et al., 2001; Scholz-Ahrens et al., 2007). The beneficial or adverse effect of bacterial cultures is not explicit, and it is often determined by the applied strain (Ghanem et al., 2004; Gilman and Cashman, 2006; Kłobukowski et al., 2009). Probiotic culture starters (Lactobacillus spp.), microflora not originating from sourdough fer- mentation, and technologically unsuitable microorganisms synthesize metabolites that affect acidity $(\mathrm{pH})$ in early stages of production and during ripening and storage. The ionization yield of mineral compounds, mostly calcium, increases with a decrease in $\mathrm{pH}$.

The rate of lactic acid fermentation determines the chemical composition of ripened cheeses, in particular in early stages of production (curd cutting, drying, supplementary drying). It is practically impossible to produce 2 batches of cheese with identical chemical composition. Automatic cheese-forming systems (Casomatic, Obram, Olsztyn, Poland) are used to minimize differences in the chemical composition of cheese. In the present study, experimental cheeses containing probiotic cultures and control cheeses differed in their chemical composition, but the observed differences were not statistically significant. Similar results were reported by other authors (Gardiner et al., 1998; El-Tanboly et al., 2010; Burns et al., 2012).

The chemical composition and acidity of fresh cheese determine its microbiological quality (i.e., the abundance of secondary microflora and technologically unsuitable microorganisms). An increase in secondary microflora counts contributes to changes in acidity during ripening. In the current study, a gradual increase in $\mathrm{pH}$ was observed in experimental and control cheeses. The addition of probiotic cultures contributed to a higher $\mathrm{pH}$ in experimental cheeses than in the control, 
both after 6 wk of ripening and 3 mo of storage. The observed differences in acidity resulted from higher Lactobacillus spp. counts in experimental cheeses, in particular in early stages of ripening (Table 2).

The rate of changes in the $\mathrm{pH}$ of cheese was one of the key determinants of calcium, magnesium, and phosphorus availability. Gradual dissociation of carboxylic acids in the aqueous phase of cheese, accompanied by a decrease in acidity, was observed in the initial stages of ripening. This led to the dissociation of mineral compounds in cheese, which substantially increased their availability. Ionized minerals easily penetrate the mucin layer and intestinal epithelial cells.

The calcium content of control cheese and experimental cheeses containing HN001 and NCFM (945, 918, and $920 \mathrm{mg} / 100 \mathrm{~g}$, respectively) was lower in comparison with experimental cheese enhanced with LPC37 $(967 \mathrm{mg} / 100 \mathrm{~g})$. Immediately after salting, the cheese containing LPC37 was characterized by higher $\mathrm{pH}$, which lowered calcium retention in whey. Ripened cheeses were more abundant in calcium than in Cheddar (721 mg/100 g; O'Brien and O'Connor, 2004) and Gouda cheese (740-880 mg/100 g; Kusiuk et al., 2008; Reykdal et al., 2011). The content of magnesium in the studied cheeses was similar, whereas the content of phosphorus was significantly lower than that reported by other authors (Gambelli et al., 1999; O'Brien and O'Connor, 2004; Kusiuk et al., 2008). The differences in the mineral content of the analyzed cheeses and the results presented by other authors can be attributed to variations in the chemical composition and starter culture used of the compared products.

The mineral compounds present in ripened cheese are not always readily available to consumers. In vitro enzymatic hydrolysis, which simulates the conditions inside the human gastrointestinal tract, demonstrated that the availability of calcium from ripened cheeses is low. The probiotic cultures used in the production of Dutch-type cheese increased calcium availability by $2.5 \%$, on average, and contributed to a significant increase in magnesium availability $(18 \%)$.

The low availability of calcium from dairy products has been demonstrated by other studies. The availability of calcium from milk and yogurt was reported at 23 to 27 and 25.4\%, respectively (Bacciottini et al. 2004; O'Brien and O'Connor, 2004). In ripened cheeses, calcium availability is determined by fat content, and it is higher in low-fat cheeses (35\%; Delisle et al., 1995) than in full-fat cheeses $(22.9 \%)$. According to (Unal et al., $2005)$, the availability of calcium from full-fat cheeses is lower $(13.85 \%)$ than from semi-fat cheeses $(24.13 \%)$. Van Dokkum et al. (1996) demonstrated that the availability of calcium from cottage cheese is relatively high, in the range of 37 to $42 \%$.
The low availability of calcium and magnesium from the analyzed cheeses can be attributed to the presence of SFA. Bond formation by bivalent metal cations is proportional to the content of SFA, in particular longchain SFA (C16 and C18), but the process does not occur evenly (Jenkins and Palmquist, 1982; Kies, 1985). In the analyzed cheeses, calcium was probably less available than magnesium due to the higher energy of ionic bonding between the $\mathrm{COO}^{-}$(carboxyl) group and calcium ions. The resulting quantity of bonded calcium can reach 42 to 57\% (Bronner and Pansu, 1999).

The availability of calcium, magnesium, and phosphorus from various ripe cheeses is also determined by proteolysis and lipolysis products. The content of bioactive peptides, including calcium phosphocaseinate (Tsuchita et al., 2001; Narva et al., 2004; Cross et al., 2005; Miquel et al., 2005), low-molecular-weight peptides (<600 Da), and free AA (Cichosz et al., 2006; Aljewicz et al., 2010), increases gradually during cheese ripening due to the activity of bacterial proteinases and peptidases. The availability of calcium and magnesium is conditioned by the chelation (formation of a covalent bond or an ionic bond between the $\mathrm{COO}^{-}$group and a metal ion or a covalent bond between an amino group and a metal ion) of metal ions by free AA, dipeptides, and tripeptides.

The results of the current study and the findings of other authors indicate that chelated minerals are characterized by higher availability (Henry, 1995). Proliferating probiotic cultures are capable of producing ionophoric peptides (bacteriocins), including rhamnosin A produced by HN001 (Dimitrijević et al., 2009) and lactocin produced by NCFM and LPC37 (Altermann et al., 2005; Uniprot, 2014). Bacteriocins form ion channels in colonocytes and facilitate ion transport. Free AA and low-molecular-weight peptides bind to FFA and metal ions, thus stimulating the availability of mineral compounds.

The stimulating effect of probiotic cultures on the availability of mineral compounds in cheese can be attributed to intensified enzymatic conversion, mainly proteolysis and lipolysis. Peptides, free AA, FFA, and their complexes with calcium, magnesium, and phosphorus ions stimulate gastrointestinal function by increasing the activity of digestive enzymes, boosting colonocyte proliferation and ion transport (Lutz and Scharrer, 1991; Banasaz et al., 2002; Scholz-Ahrens et al., 2007).

\section{CONCLUSIONS}

The cheeses containing HN001, LPC37, or NCFM probiotic cultures were characterized by lower acidity than control cheeses (without probiotic cultures). Rip- 
ened cheese is a rich source of calcium, magnesium, and phosphorus in the human diet. Cheese has a high content of SFA, and its mineral compounds are less available to consumers than the minerals present in milk and yogurt. Despite this, cheese is a much more abundant source of calcium than milk and yogurt. The use of probiotic cultures in the production of Dutch-type cheeses increased the availability of calcium, magnesium, and phosphorus. The in vitro method supports an accurate determination of the effect of the Lactobacillus spp. cultures on the availability of mineral compounds from Dutch-type cheese. The results of this study further our understanding of the interactions that determine nutrient absorption from the human gastrointestinal tract.

\section{ACKNOWLEDGMENTS}

We gratefully acknowledge financial support from the NCN (National Science Center, Warsaw, Poland; Grant No. 312469640 and 312 688840). We express our thanks to Dairy Industry in Gizycko (Poland) for assistance in the implementation experience.

\section{REFERENCES}

Aljewicz, M., G. Cichosz, and M. Kowalska. 2010. Effect of probiotic cultures Lactobacillus additive on the intensification of proteolysis in Dutch-type cheeses. Zywnosc-Nauka Technologia Jakosc 5:136-145.

Altermann, E., W. M. Russell, M. A. Azcarate-Peril, R. Barrangou, B. L. Buck, O. McAuliffe, N. Souther, A. Dobson, T. Duong, M. Callanan, S. Lick, A. Hamrick, R. Cano, and T. R. Klaenhammer. 2005. Complete genome sequence of the probiotic lactic acid bacterium Lactobacillus acidophilus NCFM. Proc. Natl. Acad. Sci. USA 102:3906-3912.

AOAC International. 2005. Official Methods of Analysis. 18th ed. AOAC International, Gaithersburg, MD.

Bacciottini, L., A. Tanini, A. Falchetti, L. Masi, F. Franceschelli, B. Pampaloni, G. Giorgi, and M. L. Brandi. 2004. Calcium bioavailability from a calcium-rich mineral water, with some observations on method. J. Clin. Gastroenterol. 38:761-766.

Banasaz, M., E. Norin. R. Holma, and T. Midtvedt. 2002. Increased enterocyte production in gnotobiotic rats mono-associated with Lactobacillus rhamnosus GG. Appl. Environ. Microbiol. 68:30313034.

Bronner, F., and D. Pansu. 1999. Nutritional aspects of calcium absorption. J. Nutr. 129:9-12.

Burns, P., F. Cuffia, M. Milesi, G. Vinderola, C. Meinardi, N. Sabbag, and E. Hynes. 2012. Technological and probiotic role of adjunct cultures of non-starter lactobacilli in soft cheese. Food Microbiol. 30:45-50.

Cichosz, G., M. Kornacki, M. Giczewska, and A. Konopka. 2006. Peptidase activity of some Lactobacillus strains. Food Sci. Tech. Qual. $1: 66-74$.

Cross, K. J., N. L. Huq, J. E. Palamara, J. W. Perich, and E. C. Reynolds. 2005. Physicochemical characterization of casein phosphopeptide-amorphous calcium phosphate nanocomplexes. J. Biol. Chem. 280:15362-15369.

Delisle, J., J. Amiot, and F. Doré. 1995. Biological availability of calcium and magnesium from dairy products. Int. Dairy J. 5:87-98.

Dimitrijević, R., M. Stojanović, I. Zivković, A. Petersen, R. M. Jankov, L. Dimitrijević, and M. Gavrović-Jankulović. 2009. The identification of a low molecular mass bacteriocin, rhamnosin A, pro- duced by Lactobacillus rhamnosus strain 68. J. Appl. Microbiol 107:2108-2115.

El-Tanboly, E.-S., M. El-Hofi, N. S. Abd-Rabou, and W. El-Desoki. 2010. Contribution of mesophilic starter and adjunct lactobacilli to proteolysis and sensory properties of semi hard cheese. New York Sci. J. 3:67-73.

FAO/WHO (Food and Agriculture Organization of the United Nations/World Health Organization). 2006. Probiotic in foods. Health and nutritional properties and guidelines for evaluation. Accessed Jan. 2014. ftp://ftp.fao.org/docrep/fao/009/a0512e/a0512e00.pdf.

Gambelli, L., P. Belloni, G. Ingrao, L. Pizzoferrato, and G. P. Santaroni. 1999. Minerals and trace elements in some Italian dairy products. J. Food Compos. Anal. 12:27-35.

Gardiner, G., R. P. Ross, J. K. Collins, G. Fitzgerald, and C. Stanton. 1998. Development of probiotic cheddar cheese containing humanderived Lactobacillus paracasei strains. Appl. Environ. Microbiol. 64:2192-2199

Ghanem, K. Z., I. H. Badawy, and A. M. Abdel-Samam. 2004. Influence of yoghurt and probiotic yoghurt on the absorption of calcium, magnesium, iron and bone mineralization in rats. Milchwissenschaft 59:472-475.

Gilman, J., and K. D. Cashman. 2006. The effect of probiotic bacteria on transepithelial calcium transport and calcium uptake in human intestinal-like Caco-2 cells. Curr. Issues Intest. Microbiol. 7:1-5.

Guéguen, L., and A. Pointillart. 2000. The bioavailability of dietary calcium. J. Am. Coll. Nutr. 19:119S-136S.

Henry, P. R. 1995. Magnesium bioavailability. Pages 201-228 in Bioavailability of Nutrients For Animals Amino Acids, Minerals and Vitamins. C. B. Ammerman, D. H. Baker and A. J. Lewis, ed. Academic Press, New York, NY.

ISO (International Organization for Standardization). 2008. ISO 3433:2008 (IDF 222: 2008) Cheese-Determination of fat content-Van Gulik method. ISO, Geneva, Switzerland.

Jenkins, T. C., and D. L. Palmquist. 1982. Effect of added fat and calcium on in vitro formation of insoluble fatty acid soaps and cell wall digestibility. J. Anim. Sci. 55:957-963.

Karczmarewicz, E., E. Skorupa, and R. S. Lorens. 2002. Wpływ probiotyków i prebiotyków na gospodarke wapniowo-fosforanów i metabolizm kostny. Pediatria Współczesna. Gastroenterologia, Hepatologia i Żywienie Dziecka 4:63-69.

Kies, C. 1985. Effect of dietary fat and fiber on calcium bioavailability. Pages $175-187$ in Nutritional Bioavailability of Calcium. ACS Symposium Series. Am. Chem. Soc., Washington, DC.

Kłobukowski, J., M. Modzelewska-Kapitula, and K. Kornacki. 2009 Calcium bioavailability from diets based on white cheese containing probiotics or synbiotics in short-time study in rats. Pak. J. Nutr. 8:933-936.

Kneifel, W., S. Salminem. 2011. Probiotics and Health Claims. 1st ed. Wiley-Blackwell, Hoboken, NJ.

Kusiuk, A., M. Trembecka, and P. Szefer. 2008. Zawartość magne$\mathrm{zu}$, popiołu i wody w różnych serach twardych. Bromatologia Chemia Toksykologiczna 3:365-368.

Kwong, W., and D. D. Kitts. 2003. Calcium bioavailability of dairy components. Pages 69-190 in Handbook of Functional Dairy Products. C. Shortt and J. O'Brien, ed. CRC Press, Boca Raton, FL.

Lutz, T., and E. Scharrer. 1991. Effect of short-chain fatty acids on calcium absorption by the rat colon. Exp. Physiol. 76:615-618.

Miquel, E., J. A. Gomez, A. Alegria, R. Barbera, R. Farre, and I. Recio. 2005. Identification of casein phoshopeptides released after simulated digestion of milk-based infant formulas. J. Agric. Food Chem. 53:3426-3433.

Narva, M., J. Halleen, K. Vaananen, and R. Korpela. 2004. Effects of Lactobacillus helveticus fermented milk on bone cells in vitro. Life Sci. 75:1727-1734

O'Brien, N. M., and T. P. O'Connor. 2004. Nutritional aspects of cheese. Pages 573-581 in Cheese: Chemistry, Physics and Microbiology. P. F. Fox, P. L. H, McSweeney, T. M. Cogan, and T. P. Guinee, ed. Academic Press, New York, NY.

PKN (Polski Komitet Normalizacyjny). 1999. PN-ISO 13730:1999/ Ap1:2004 Meat and meat products - Determination of total phos- 
phorus content-Spectrophotometric method. PKN, Warsaw, Poland.

PKN (Polski Komitet Normalizacyjny). 2013. PN-EN ISO 7218:2008 Microbiology of food and animal feeding stuffs - General requirements and rules for the microbiological testing. PKN, Warsaw, Poland.

Reykdal, O., S. Rabieh, L. Steingrimsdottir, and H. Gunnlaugsdottir. 2011. Minerals and trace elements in Icelandic dairy products and meat. J. Food Compos. Anal. 24:980-986.

Scholz-Ahrens, K. E., A. Peter, M. Berit, and W. Petra. 2007. Prebiotics, probiotics and synbiotics affect mineral absorption, bone mineral content and bone structure. J. Nutr. 137:838S-846S.

Tsuchita, H., T. Suzuki, and T. Kuwata. 2001. The effect of casein phosphopeptides on calcium absorption from calcium-fortified milk in growing rats. Br. J. Nutr. 85:5-10.
Unal, G., S. N. El, and S. Kiliç. 2005. In vitro determination of calcium bioavailability of milk, dairy products and infant formulas. Int. J. Food Sci. Nutr. 56:13-22.

Uniprot. 2014. K6S485: Class IIb bacteriocin from Lactobacillus casei Lpc-37. Accessed Feb. 14, 2014. http://www.uniprot.org/uniprot/ K6S485.

Van Dokkum, W., V. De La Guéronnière, G. Schaafsma, C. Bouley, J. Luten, and C. Latgé. 1996. Bioavailability of calcium of fresh cheeses, enteral food and mineral water. A study with stable calcium isotopes in young adult women. Br. J. Nutr. 75:893-903.

Whiteside, P. J. 1979. Atomic Absorption Data Book. 3rd ed. Pye Unicam Ltd., Cambridge, UK.

Wolf, R. L., J. A. Cauley, C. E. Baker, R. E. Ferrell, M. Charron, and A. W. Caggiula. 2000. Factors associated with calcium absorption efficiency in pre-and perimenopausal women. Am. J. Clin. Nutr. $72: 466-471$ 